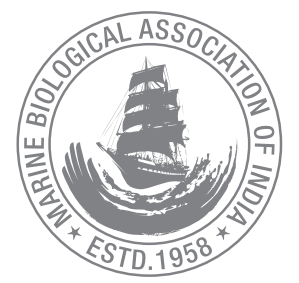

\title{
Vulnerability of south east coastal villages of India on sea level rise
}

\author{
V. S. Haritha', K. R. Sreenath*, M. Anakha, K. K. Joshi and P. Shelton \\ ICAR-Central Marine Fisheries Research Institute, Kochi - 18, India. \\ 'School of Ocean Engineering and Underwater Technology, KUFOS, Kochi-06, India. \\ *Correspondence email: sreenath.ramanathan@icar.gov.in
}

Received: 06 April 2019 Accepted: 10 June 2019 Published: 30 June 2019

Original Article

\begin{abstract}
Sea level rise is one of the evident ill effects of climate change. As per the fifth assessment report of IPCC the rate of sea level rise has increased in recent years as compared to the previous years. The rapid rise in sea level can have devastating effects on the densely populated coastal areas, mainly by way of inundation of low lying habitats. Inundation of highly populated coastal areas exposes the location to coastal hazards and increases the risk to both life and belongings of people at the location. Therefore, identification of vulnerable areas becomes necessary for coastal zone management. The present study maps the Low Elevation Coastal Zones (LECZ) of Andhra Pradesh and Tamil Nadu and estimates the vulnerability of each coastal village based on population and elevation. The coastal villages with high percentage of low elevation zones and high population density are the most vulnerable areas and a vulnerability index is formulated as a product of these two variables. Landforms along Andhra Pradesh and Tamil Nadu coast include low lying alluvial plains, bays, tidal mudflats, creeks, ridges, bars, spits, mangrove swamps, marshes, and lagoons, which are subject to sea level rise. Maps for the study were produced using ArcGIS 10. The boundary maps were collected from the DataMeet project and the elevation data from ETOPO1. Population density data were collected from the NASA Socioeconomic Data and Applications Center (SEDAC). Increase in water level leads to higher rates of erosion that result in beach loss, enhancing the vulnerability of
\end{abstract}

the coastal area to hazards. The analysis shows that Losari Gutlapadu and Sadayankuppam are the most vulnerable villages in Andhra Pradesh and Tamil Nadu respectively. Mapping of the vulnerable areas act as advisories and can help the state governments to develop mitigation strategies.

Keywords: LECZ, coastal vulnerability, sea level rise, population density

\section{Introduction}

Coastal zone is a dynamic area with many cyclic processes involving a variety of resources and habitats. A coastal region is a place of hectic human activity due to urbanization and industrialization. The Indian east coast stretches from West Bengal to Tamil Nadu, has a narrow continental shelf and wide stretch of coastal belt with bays, estuaries, lagoons, deltas and some small islands and salt marshes. Major coastal landforms along Andhra Pradesh and Tamil Nadu coast are alluvial plains, bays, tidal mudflats, creeks, ridges, bars, spits, mangroves, marshes, and lagoons. These landforms are highly prone to climate change induced sea level rise and coastal erosion (Pramanik et al., 2015). 
The Intergovernmental Panel on Climate Change (IPCC) fifth assessment report projects approximately 1-meter sea level rise (SLR) across the globe in 2100. High projected rates of future sea level rise have raised concern all over the world. Low elevated coastal regions are vulnerable to natural calamities due to their proximity to the sea, large concentrations of population and persistent economic activities (Islam et al., 2016). Contiguous areas along the coast that are less than $10 \mathrm{~m}$ above sea level are designated as the Low Elevation Coastal Zone (LECZ) (Mcgranahan et al., 2007) and these areas are subject to coastal hazards such as storm surges, coastal erosion and saltwater intrusion into coastal aquifers and estuaries on a large scale due to their low elevation and the increase of sea level adjacent to these areas (Barbier, 2015). One important factor that determines vulnerability is the elevation of the region, as inundation depends on it.

Andhra Pradesh holds second position and Tamil Nadu third among the maritime states of India in terms of length of coastline with 973.7 and $906.9 \mathrm{~km}$ respectively. They are potential hot spots where the immediate effects of sea level rise may be observed. One of the profound effects is the enhanced rate of erosion which leads the beaches into a bizarre situation (Williams, 2013). They are subject to frequent wraths of cyclones and storms (Barbier, 2015). The destruction of such an area would jeopardize their ecosystem on a large scale.

Against this backdrop, the present study focuses on the thematic mapping of the physical vulnerability of coastal villages of Andhra Pradesh and Tamil Nadu to an increase in sea level rise.

\section{Material and methods}

\section{Data}

Coastal villages along Andhra Pradesh and Tamil Nadu states were the focus of the present study. The data on the boundary of the villages were obtained from the DataMeet project (2018). ETOPO1 (Christopher, 2009) of 30 arc second resolution was used for identifying the LECZ areas. The population density data were collected from SEDAC with 30 arc second resolution (2015).

\section{Data analysis and mapping}

The GIS-based maps were produced using ArcGIS 10. The LECZ of each coastal village of Andhra Pradesh and Tamil Nadu were extracted using the Raster calculator function of ArcGIS. The elevation map and the boundary map were clipped together to calculate the area of LECZ in each village. The percentage of the LECZ area in each village was plotted. The areas with an elevation below sea level were not considered for this analysis.
Village wise average population density was estimated using the Zonal statistics tool and plotted using classified symbology to make the maps. To understand the vulnerability of each village, a vulnerability index value has been estimated. The index allows the two physical variables to be related in a quantifiable manner. This method yields numerical data that cannot be directly equated with particular physical effects. It does, however highlight those regions where the various effects of sea-level rise may be the greatest. The coastal vulnerability index is calculated as a product of the percentage of LECZ per village and its average population density.

\section{Results}

LECZ along the southeast coast of India was found to occupy more than 50 percent of the coastal village area (Fig. 1). The population density was also higher in coastal areas of Andhra Pradesh and Tamil Nadu as compared to the inland area. There are 2684 coastal villages in Andhra Pradesh, out of which 1249 villages had 100 percent of LECZ area (Fig. 2). Guntur, Krishna, West Godavari Districts had the highest LECZ area. Andhra Pradesh has 71 percent of coastal villages in Low Elevation Coastal Zone. Some of the forest areas were also found to be under the LECZ of Andhra Pradesh. Tamil Nadu has 2607 coastal villages among which 863 villages had 100 percent of LECZ area. Thiruvarur, Nagapattinam, Cuddalore, Thiruvallur, Chennai, Ramanathapuram were the coastal districts with the highest LECZ area. 67.34 percentage of the coastal villages are lying under LECZ in Tamil Nadu (Fig. 3).

The vulnerability index of Andhra Pradesh and Tamil Nadu ranged from 0 to 5882690 and 0 to 6450606 respectively. The value zero indicates absence of population and these areas may be forest, wetlands or water body. The population density in Andhra Pradesh was highest at Gangadipalam, Visakhapatnam, Ramakrishnapuram, Kandukur villages (Fig. 4), but the vulnerability index value was highest, (5882690) in the village Losari Gutlapadu followed by Pedalanka (4891226), Vallur(4759030) and Allure (4362444) (Fig. 5). The highly populated village (Gangadipalam) and most vulnerable village (Losari Gutlapadu) in the state of Andhra Pradesh have been marked in figures 4 and 5 respectively. West Godavari was the most vulnerable district in Andhra Pradesh as per the vulnerability index value of its coastal villages.

Sadayankuppam, Vilangadupakkam, Ariyalur, Mathur and Pambam were the coastal villages in Tamil Nadu with larger LECZ area as well as higher population density (Fig. 6). Subsequently, the vulnerability index values for these villages were 6450606 , $5605236,4525721,3561346$ and 3482885 respectively. In the state of Tamil Nadu, Sadayankuppam is the highly populated village (marked in figure 6) and it has also been found to be 


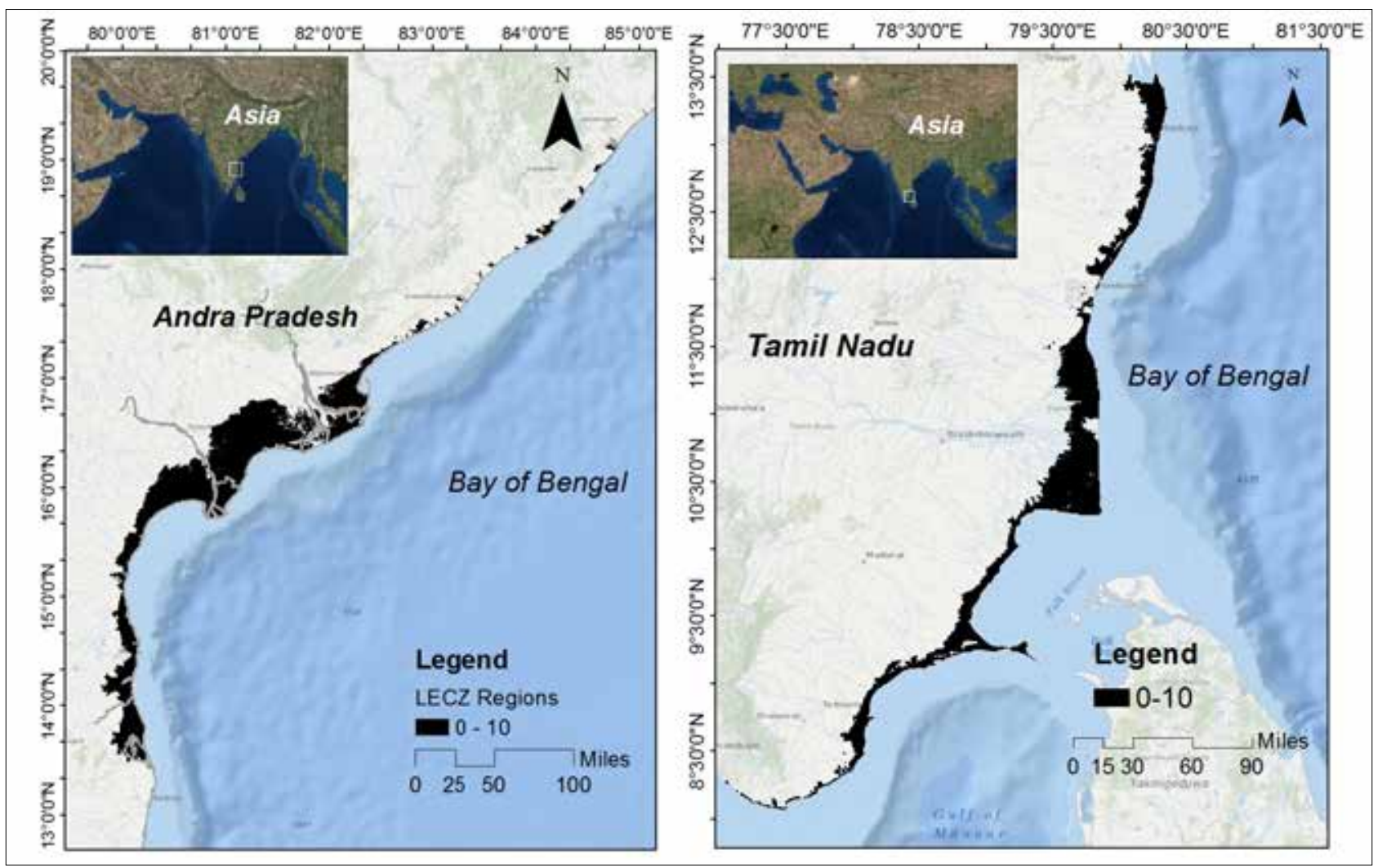

Fig. 1. LECZ Region of Andhra Pradesh and Tamil Nadu

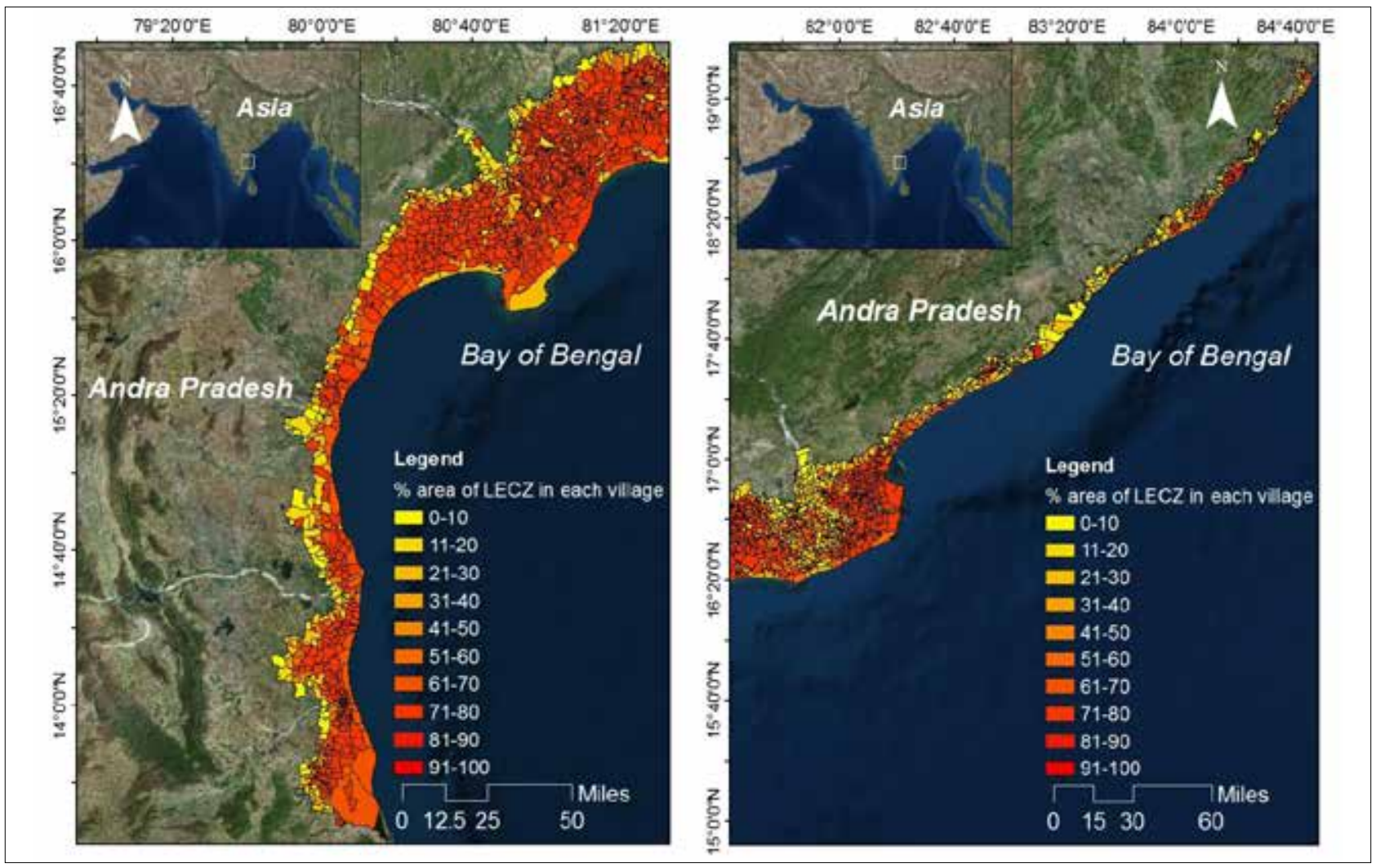

Fig. 2. Percentage area of LECZ in each village of Andhra Pradesh 


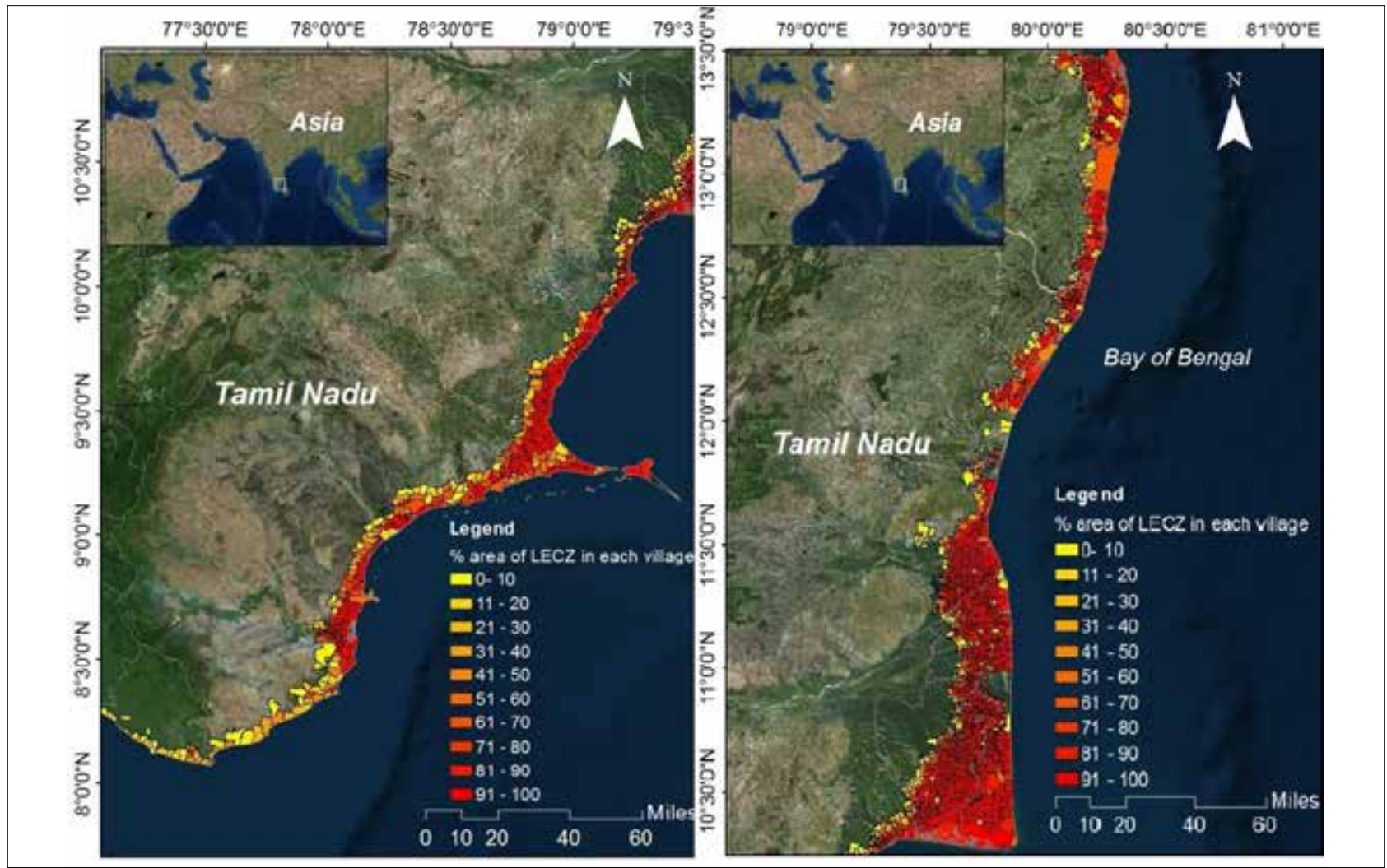

Fig. 3. Percentage area of LECZ in each village of Tamil Nadu

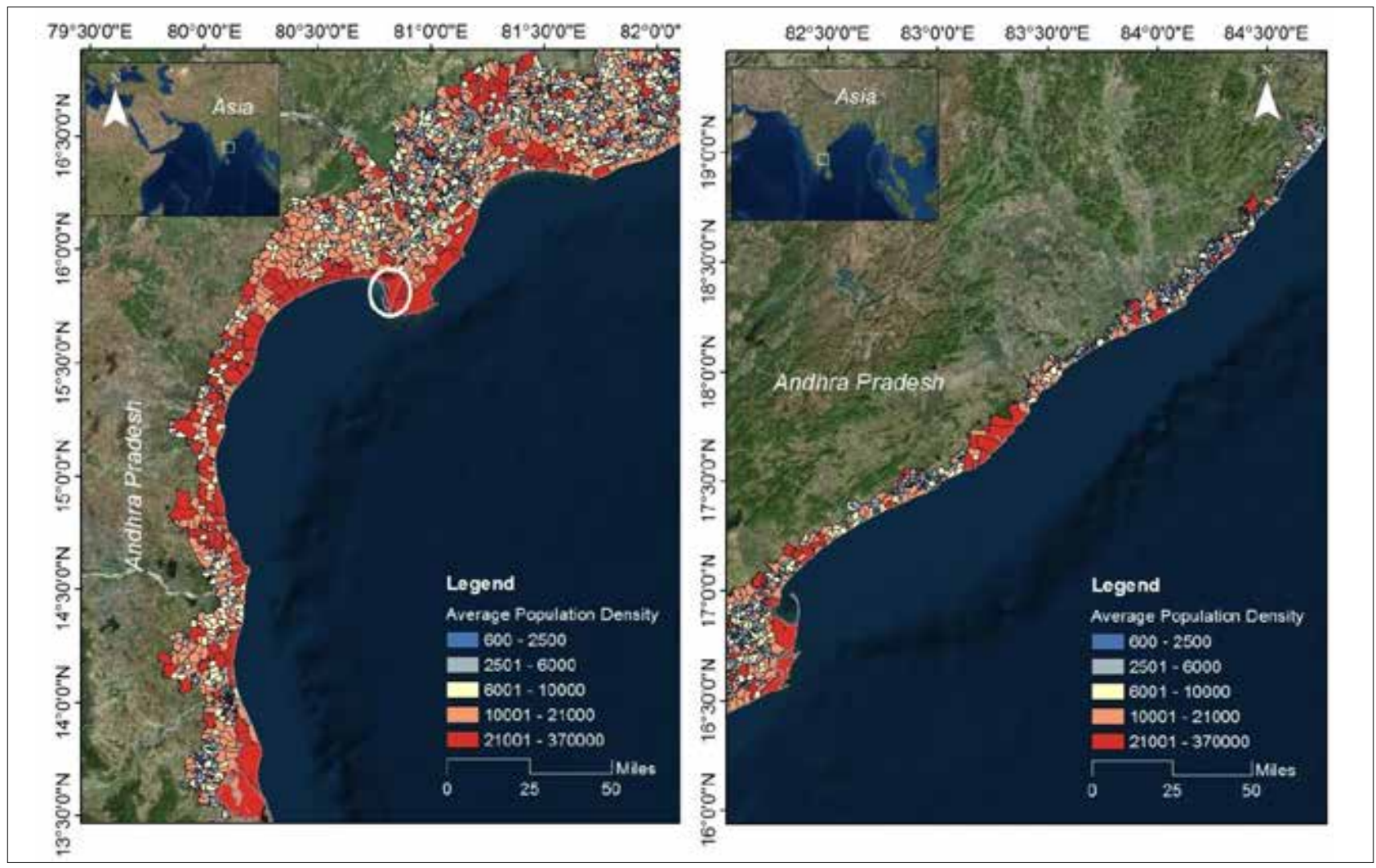

Fig. 4. Average Population Density in each village of Andhra Pradesh 


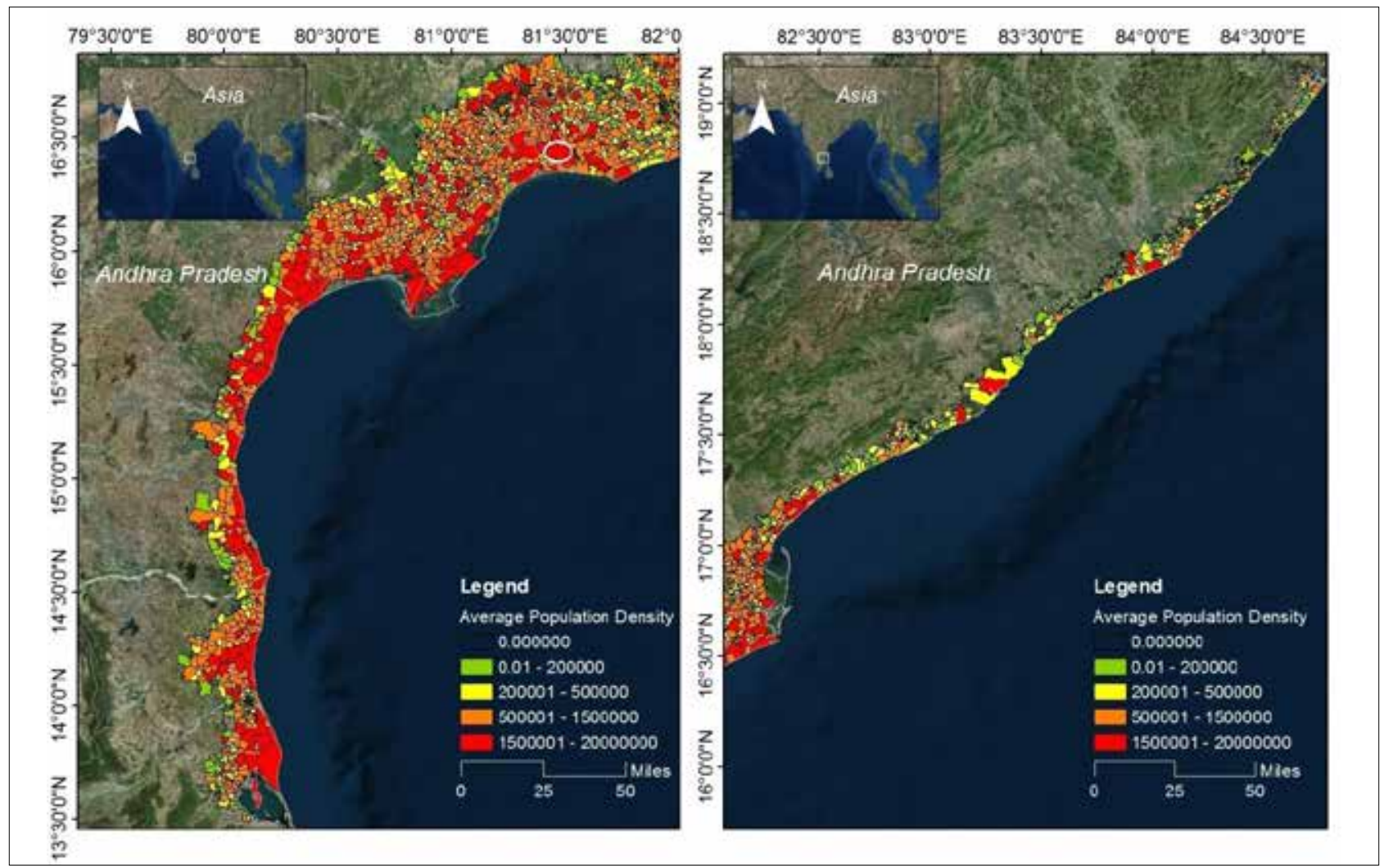

Fig. 5. Vulnerability Index of Andhra Pradesh

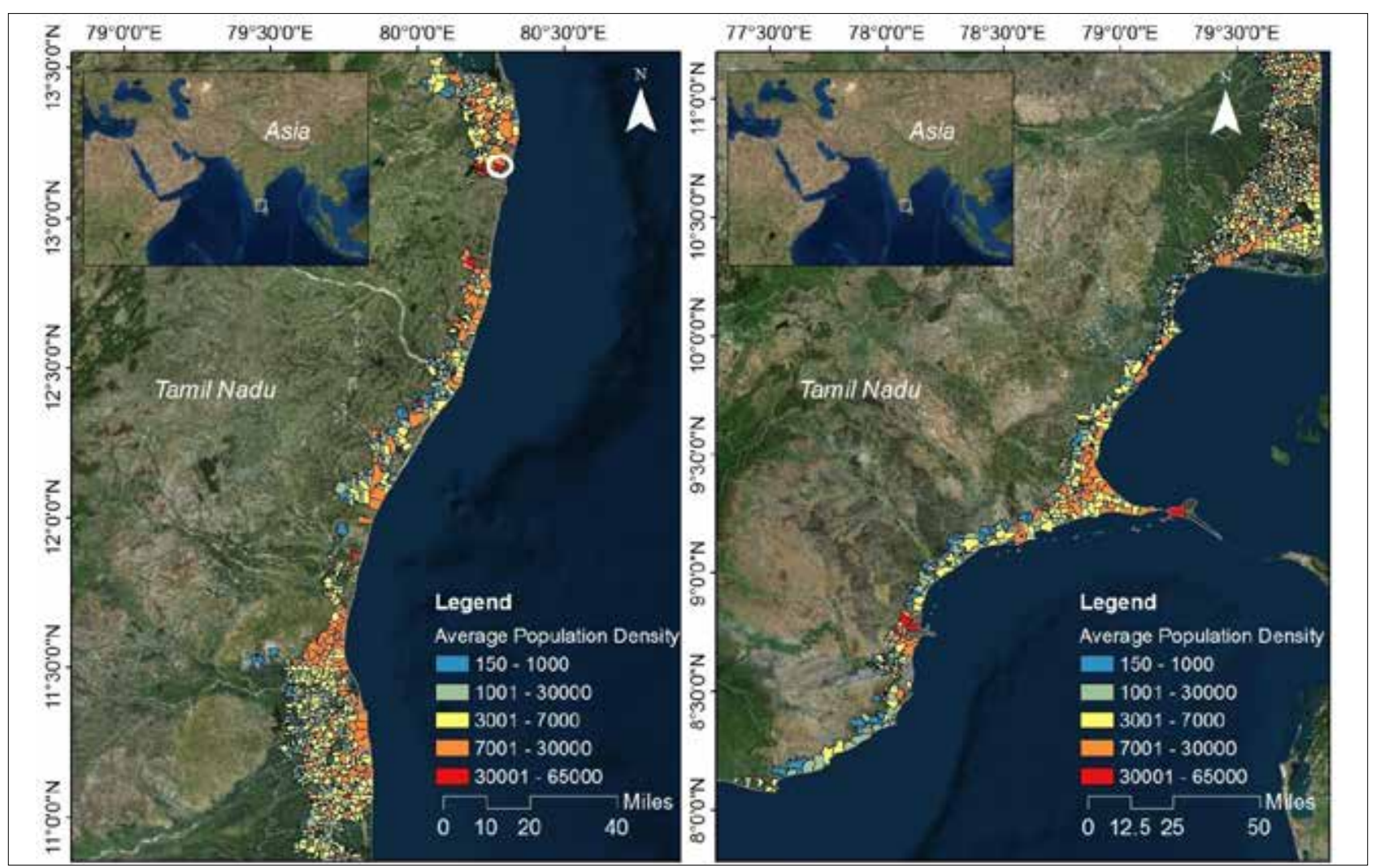

Fig. 6. Average Population Density of Tamil Nadu 


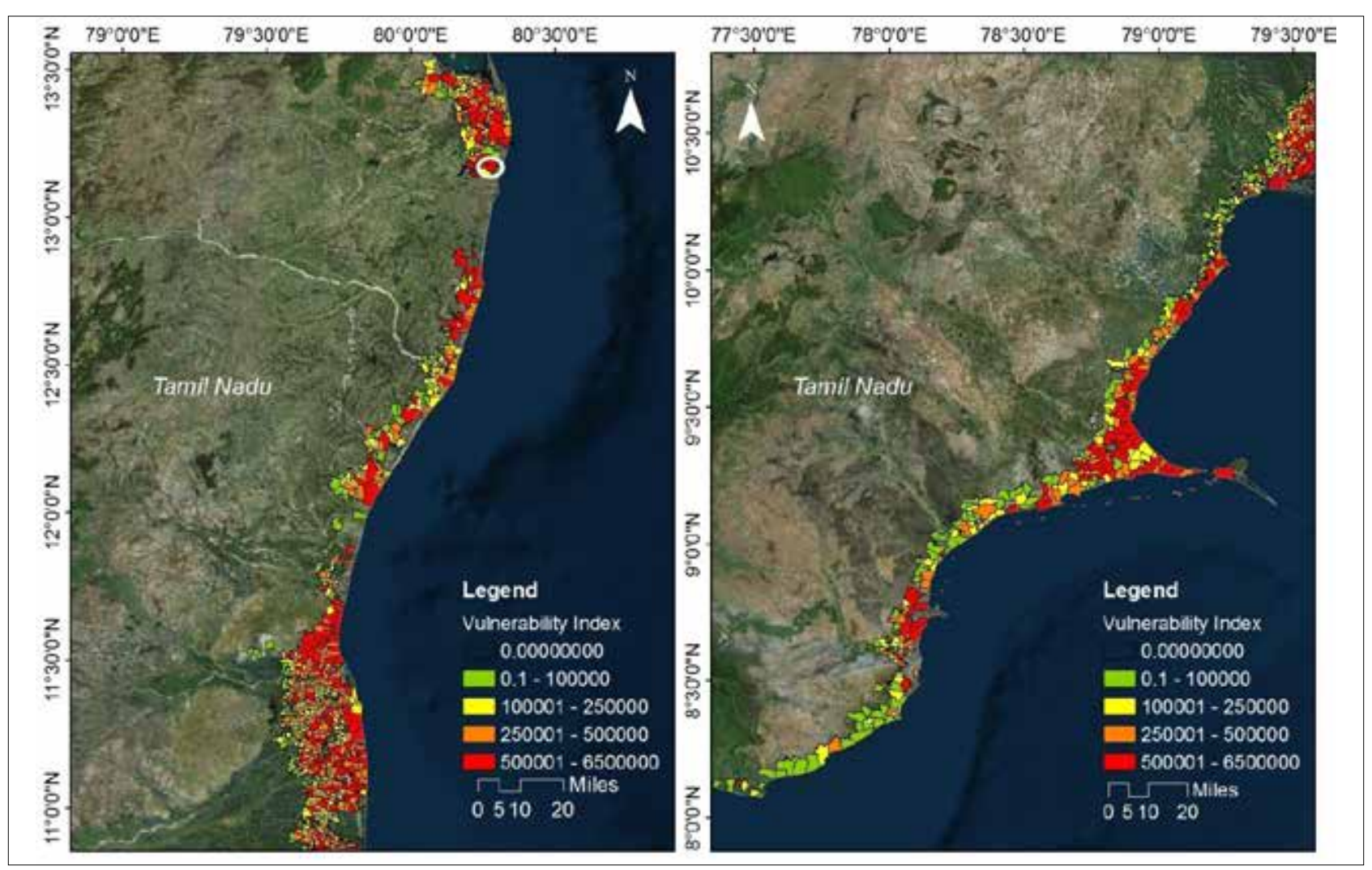

Fig. 7. Vulnerability Index of Tamil Nadu

the most vulnerable village (marked in figure 7). Nagapattinam was the most vulnerable district in Tamil Nadu with a higher vulnerability index (Fig.7).

\section{Discussion}

Coastal elevation and population are two major factors that which determine the vulnerability of coastal zones as the elevation represents a physical variable and population, a socioeconomic variable (Islam et al., 2016). The results of this study indicate that the majority of the coastal areas of Andhra Pradesh and Tamil Nadu have LECZ. In 1843 villages of Andhra Pradesh and 1487 villages of Tamil Nadu, more than $50 \%$ of the coastal area is observed to be lying in LECZ, making the habitats highly susceptible to coastal hazards. According to the Intergovernmental Panel on Climate Change 5th Assessment Report (IPCC, 2014), the risk to low lying areas, especially along the coastal belt, is projected to increase significantly throughout the 21 st century and beyond. Rising sea levels are already eroding shorelines of the Indian coast, slowly drowning low-lying areas, and changing shoreline configuration of the coast. These changes in sea level coupled with high tides, waves and storm surges can cause excessive episodic flooding. Such flooding affects the ecosystems, settlements, port operations and ultimately the livelihood of coastal communities leading to migration of local people to other areas (Nayak, 1994). As the rate of sea level rise increases, the effects will continue in the future. The coastal zone would be permanently inundated to an elevation equivalent to the vertical rise in sea level. The effects of the global SLR on the shoreline will be spatially non-uniform because of the presence of local vertical crustal movements, differential resistance to erosion, varying wave climates and long shore currents (Gornitz et al., 1991). However, episodic flooding from storm waves could add to the damage by penetration of seawater further inland. Enhanced erosion rates would threaten beaches and coastal structures (Mimura, 2013). Finally, increasing salinization of coastal aquifers and upstream penetration of saltwater resulting from the SLR could contaminate drinking water supplies and adversely affect agriculture.

The Indian east coast is consistently threatened by natural hazards (Pramanik et al., 2015). The presence of low elevated areas with higher population density increases the risk at these locations. The escalation in the rate of sea level rise will increase the impacts of natural hazards in the future. Management of hazards in villages with 100 percent LECZ would be very difficult. The villages with higher vulnerability require special disaster management plans. The recent studies reveal the need to model the impacts of coastal hazards and design adaptive and mitigation strategies for the sustainable development of the 
coastal zone. Geospatial information technology can contribute greatly to develop such models (Nayak, 2017). The current study has identified the most vulnerable coastal villages through the vulnerability mapping of LECZ regions based on average population density and hence can aid in the development of disaster management plans for the east coast of India. Further, construction for commercial purposes and occupation of land area for housing purposes should be discouraged from the LECZ areas so that risk can be reduced in case of any hazards. The assessment of the vulnerability of coastal zones is possible with the help of remote sensing and GIS. The methodology adopted in this study can be automated for large scale vulnerability assessments. Improved understanding of sea-level rise and variability will help in designing strategies that serve to mitigate the damages caused by SLR, thus enabling better coastal zone management and planning.

\section{Acknowledgements}

We are grateful to Dr. Gopalakrishnan, Director, CMFRI, Kochi for the support and encouragement during the course of this study. We thank Prof. Dr. Suriyakala C. D, Director, School of Ocean Engineering and Underwater Technology, KUFOS for the support rendered during this study.

\section{References}

Barbier, E. B. 2015. "Climate Change Impacts on Rural Poverty in Low-Elevation Coastal Zones (English)", Policy Research working paper, no. WPS 7475. Washington, D. C.: World Bank Group.

Christopher, A. 2009. ETOPO1 1 arc-minute global relief model: procedures, data sources and analysis. Boulder, Colo.: U.S. Dept. of Commerce, National Oceanic and Atmospheric Administration, National Environmental Satellite, Data, and Information Service, National Geophysical Data Center, Marine Geology and Geophysics Division

Gornitz, V., T. W. White and R. M. Cushman.1991. "Vulnerability of the US to Future Sea Level Rise." Oak Ridge National Lab., TN (USA). https://www.osti.gov/ biblio/5875484.

IPCC. 2014. 5th Assessment Report.

Islam Md, M. Debashis, A. Dewan and A. Syed. 2016. Coastal multi-hazard vulnerability assessment along the Ganges deltaic coast of Bangladesh-A geospatial approach. Ocean \& Coastal Management, 127:1-15.

McGranahan, G., D. Balk, and B. Anderson. 2007. "The Rising Tide: Assessing the Risks of Climate Change and Human Settlements in Low Elevation Coastal Zones." Environment and Urbanization, 19 (1): 17-37.

Mimura, N. 2013. "Sea-level rise caused by climate change and its implications for society," Proceedings of the Japan Academy. Series B, Physical and Biological Sciences, 89 (7): 281-301.

Nayak, S. 1994. "Application of Remote Sensing Data for Estimation of Impact of Sea Level Rise Along the Gujarat Coast." In Global Change Studies. Scientific Results from ISRO Geoshere Biosphere Programme, 337-348. ISRO-GBP-SR-42-94. Bangalore: Indian Space Research Organisation.

Nayak, S. 2017. "Coastal Zone Management in India - Present Status and Future Needs." Geo-Spatial Information Science, 20 (2): 174-83.

Pramanik, M. K., S. S. Biswas, T. Mukherjee, and A. K. Roy, 2015. "Sea Level Rise and Coastal Vulnerability along the Eastern Coast of India through Geo-Spatial Technologies." J Remote Sensing \& GIS, 4 (2): 1-8.

Williams, S. J. 2013. "Sea-Level Rise Implications for Coastal Regions." Journal of coastal region, 63(1): 184-96 